\title{
Variations of urban greenness across urban structural units in Beijing, China
}

\author{
Hua-Feng Wang ${ }^{a, *}$, Jiang-Xiao Qiu ${ }^{b}$, Jürgen Breuste ${ }^{c}$, Cynthia Ross Friedman $^{\mathrm{d}}$, \\ Wei-Qi Zhou ${ }^{a}$, Xiao-Ke Wang ${ }^{a}$ \\ a Beijing Urban Ecosystem Research Station, State Key Laboratory of Urban and Regional Ecology, Research Center for Eco-Environmental Sciences, Chinese \\ Academy of Sciences, 100085 Beijing, China \\ ${ }^{\mathrm{b}}$ Department of Zoology, University of Wisconsin-Madison, Madison, WI 53706, USA \\ ' Urban and Landscape Ecology, IALE Centre for Landscape Research (CeLaRe), University Salzburg, Dept. Geography/Geology, Hellbrunnerstrasse 34, A 5020 \\ Salzburg, Austria \\ d Department of Biological Sciences, Thompson Rivers University, Box 3010, 900 McGill Road, Kamloops, British Columbia V2C 5N3, Canada
}

\section{A R T I C L E I N F O}

\section{Keywords:}

Land use

Land cover

Green spaces

Urban structural unit

\begin{abstract}
A B S T R A C T
Urban structural units (USUs) are work (or similar) units in urbanized areas. In this study, USUs based on urban land use and land cover were used to explain and compare urban ecological conditions within Beijing. This study focused on the spatial pattern of land use for different USUs in urban areas. The results showed that 453 USUs belong to 12 primary USUs and to 38 different secondary USUs. The percentage of built-up area was highest in those regions with hotels, and lowest in areas with cemeteries. The percentage of woodland area was highest in primary and middle schools, and the lowest in entertainment plazas. The percentage of grassland area was highest in farmland or orchards, and lowest in Siheyuan (courtyards). The percentage of green space is highest in lands dedicated to middle and primary schools, and lowest in areas with museums. There is no significant linear relationship between construction period and green space percentage in Colleges/Universities $(R=0.045, p=0.806>0.05)$ and $\operatorname{Parks}(R=0.13$, $p=0.43>0.05)$. However, there was an inverted-U curve relationship with the relevant housing price in the residential area, a relationship that can be described by the equation: $f=17736.45+348.21 x-4.15 x^{2}$, $p=0.0022<0.05$. This relationship implied that the socio-economic factors like housing prices may be a factor in determining the green space pattern of urban ecosystems in Beijing.
\end{abstract}

(C) 2013 Elsevier GmbH. All rights reserved.

\section{Introduction}

Urbanization has brought dramatic land use/land cover changes, and has thus become a leading issue in ecological and socioeconomic research (Ma and Wang, 1984; Grimm et al., 2000, 2008; Pickett et al., 2001; Alberti and Marzluff, 2004; Wang and Ouyang, 2012; Szantoi et al., 2012). Urban areas are dominated by highly dynamic and heterogeneous landscapes that result from the interactions between humans and the natural environment (Alberti, 2005). By measuring and comparing spatial and temporal variation of urban patches as well as ecosystem characteristics and their links or processes, it is possible to reveal some of the mechanisms by which urban ecosystems operate (Buyantuyev, 2008; Breuste and Qureshi, 2011). Conversion of land use in urbanization processes can be investigated quantitatively and displayed in thematic maps (Dunn et al., 1991; Gustafson, 1998; Li and Wu, 2007), in which

\footnotetext{
* Corresponding author. Tel.: +86 1062849751.

E-mail address: hfwang@rcees.ac.cn (H.-F. Wang).
}

each patch represents a unique land use/land cover (LULC) pattern integrated in urban structural units (USUs). These thematic LULC and USU maps are often generated by the interpretation of remote sensing images (Buyantuyev, 2008; Wu, 2008).

Urban green space has been called "green lungs", since this green infrastructure is an important life support system in urban ecosystems (Wang and Liu, 2010). Degradation and loss of green space may harm the habitat, reduce biodiversity, and affect pattern and ecological processes in urban ecosystems (Breuste and Wohlleber, 1998; Kim and Pauleit, 2007). In contrast, the presence of urban green space will alleviate these problems by helping to restore the normal energy flow (Yeh and Huang, 2009), cleaning air and water (Davies et al., 2008), and providing more opportunities for esthetic enjoyment, recreation, and relaxation (Chen and Jim, 2008). Urban green space will also help slow down the "urban heat island effect", the effect in which a metropolitan area is significantly warmer than surrounding rural areas (Xiao, 2006; Yuan and Bauer, 2007). However, urbanization also causes urban vegetation pattern variation and decreases plant diversity, both of which have a serious impact on the city's ecosystem structure, function, and stability 
(Wang et al., 2004). At present, two serious problems exist in the urban green space of China's major cities: firstly, the per capita urban green space area in China is very small. For example, the urban greening area per capita in Beijing is only $50 \%$ of that in Paris, and only $17 \%$ of that in London (BSRC, 2009). Secondly, $53 \%$ of the green space in Beijing is made up of alien plant species (Zhao et al., 2010a; Wang et al., 2011).

The specific socioeconomic factors are not the same in different places around the world. For example, in Chicago, IL, USA, household income and household density are strongly related to land cover (Iverson and Cook, 2000). The higher socioeconomic strata in Santiago, Chile had fewer public trees as well as greater tree cover, greater tree and leaf area density, and greater leaf area index than lower socioeconomic strata (Escobedo et al., 2006). Luck et al. (2009) found that vegetation cover had a negative quadratic relationship with neighborhood housing density - peaking at middensity values - and had a positive relationship with education level and immigration status in Victoria and New South Wales, Australia (Luck et al., 2009). A study by Troy et al. (2012) found a strong inverse relationship between tree canopy and these authors' novel index of robbery, burglary, theft and shootings in Baltimore City. Education and income is highly correlated with tree cover and housing tenure (rented-owned) in Miami, FL, USA (Szantoi et al., 2012). However, the dynamics of landscape composition in response to urbanization are poorly understood. Moreover, the relationship between green space cover and its influencing factors has rarely been discussed in Beijing (Wang et al., 2012). Further theoretical discussion and empirical verification of landscape diversity in urban regions is thus required. Therefore, this study examines the spatial pattern of land use of different structural units in urban areas and addresses the following research questions: (1) What are the land cover patterns across USUs in a rapid growing urbanized area? (2) How do the socio-economical factors influence the percentage of urban green space in some USUs?

In this study, we analyzed the land use patterns of different structural units and socio-economic factors within the fifth-ring road of Beijing, China, the densely built-up area of this megacity. This work aims to provide a better understanding of urban green space patterns and possible functioning for future urban planning, development, and management in a rapidly urbanizing and growing city.

\section{Methods}

\section{Study area}

Beijing has a monsoon-influenced continental climate (Markus et al., 2006) characterized by hot, humid summers due to the East Asian monsoons, and generally cold, windy, dry winters that reflect the influence of the vast Siberian anticyclone (Beijing, 2008). Beijing's annual temperature is $11.7^{\circ} \mathrm{C}$, and the annual average precipitation, which mainly occurs in summer, is $595 \mathrm{~mm}$. As the political and cultural center of China, Beijing occupies $16,807.8 \mathrm{~km}^{2}$, and the central urban area $\left(652.2 \mathrm{~km}^{2}\right)$ confined within the fifth ring road (Fig. 1) is $652.2 \mathrm{~km}^{2}$ (BISM, 2005). In 2009, Beijing's population reached 17.55 million (SBBC, 2008).

\section{Definition of urban structural units}

The 12 primary urban structural units (USUs) in Beijing are defined by the Urban Forest Effects (UFORE) Model: Field Data Collection Manual (UFORE, 2012); see Table 1 for details. 'Agriculture' (A) includes greenbelts, woodlands, nurseries, and farmland or orchards. 'Cemetery' (E) is cemetery land. 'Commerce/Industry' (C) includes hotels, businesses, and logistics centers. 'Golf courses' (G) are self-evident. 'Institutional' (I) includes museums, colleges/universities, research institutions, places of historic interest and scenic beauty, general institutions, primary and middle schools. 'Multifamily residential' (M) are defined as residential buildings for more than three families. 'Park' $(\mathrm{P})$ are parklands. 'Residential' ( $R$ ) includes urban villages, low-density residential areas, and Siheyuan (Courtyards). 'Transportation' (T) includes

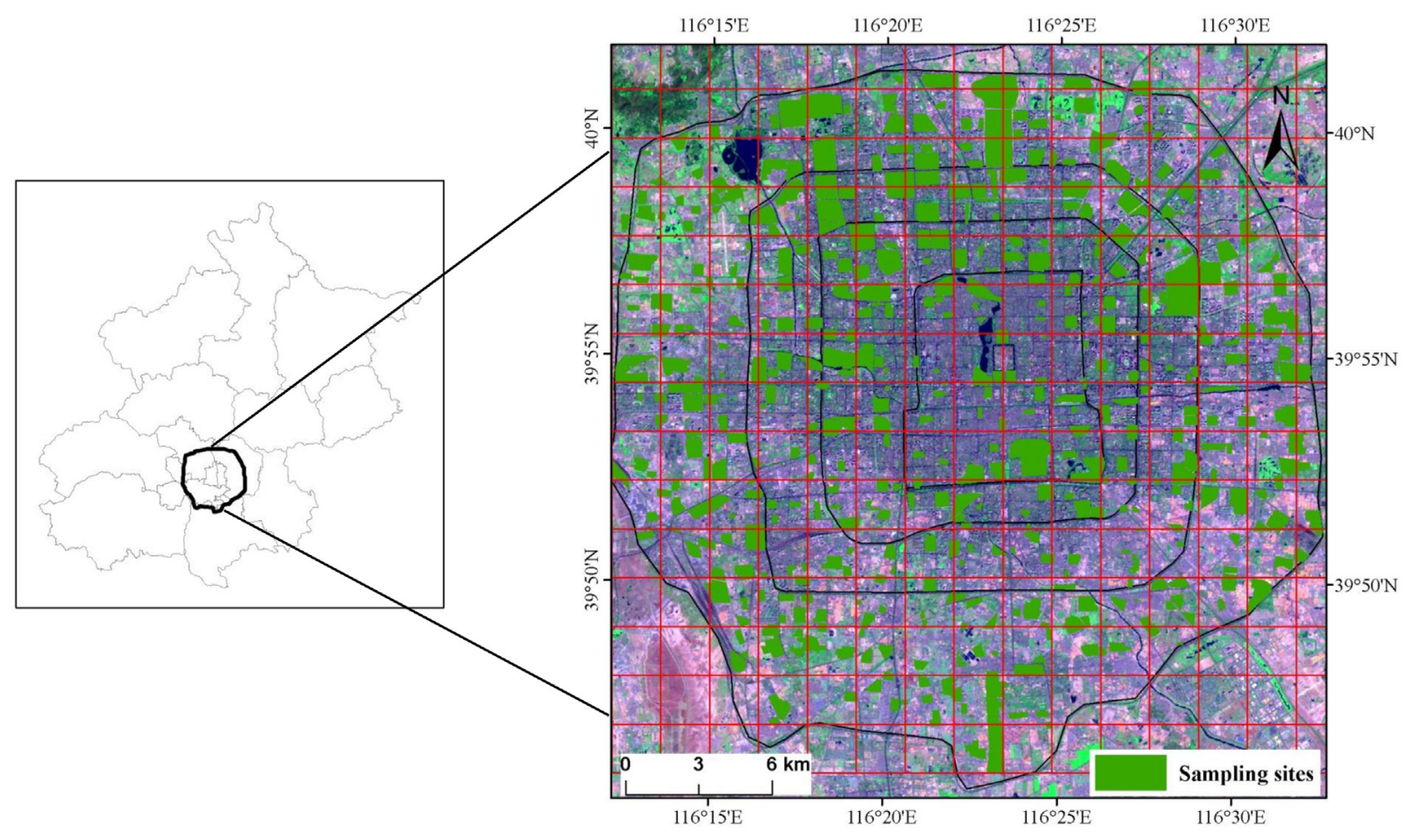

Fig. 1. The 453 urban structural units within the fifth ring road of Beijing, China. 
Table 1

The statistical results of secondary urban structural districts.

\begin{tabular}{|c|c|c|c|}
\hline Primary urban structural unit type & Secondary urban structural unit type & Number & Percentage (\%) \\
\hline \multirow{4}{*}{ Agriculture (A) } & Greenbelt & 4 & 0.88 \\
\hline & Woodland & 1 & 0.22 \\
\hline & Nursery & 1 & 0.22 \\
\hline & Farmland or orchard & 7 & 1.55 \\
\hline Cemetery (E) & Cemetery & 3 & 0.66 \\
\hline \multirow{4}{*}{ Comm/Ind (C) } & Shopping center & 2 & 0.44 \\
\hline & Hotel & 3 & 0.66 \\
\hline & Enterprise & 27 & 5.96 \\
\hline & Logistics center & 8 & 1.77 \\
\hline Golf course $(G)$ & Golf course & 2 & 0.44 \\
\hline \multirow{6}{*}{ Institutional (I) } & Museum & 6 & 1.32 \\
\hline & College or university & 46 & 10.15 \\
\hline & Research institution & 8 & 1.77 \\
\hline & Places of historic interest and scenic beauty & 2 & 0.44 \\
\hline & General institution & 10 & 2.21 \\
\hline & Primary and middle schools & 34 & 7.51 \\
\hline Multi family residential (M) & High density residential area & 94 & 20.75 \\
\hline Park (P) & Park & 47 & 10.38 \\
\hline \multirow{3}{*}{ Residential (R) } & Urban village & 3 & 0.66 \\
\hline & Low density residential area & 66 & 14.57 \\
\hline & Siheyuan (courtyard) & 2 & 0.44 \\
\hline \multirow{6}{*}{$\begin{array}{l}\text { Transportation } \\
(\mathrm{T})\end{array}$} & Overpass bridge & 2 & 0.44 \\
\hline & Road and express & 8 & 1.77 \\
\hline & Bus stop & 1 & 0.22 \\
\hline & Train station & 5 & 1.10 \\
\hline & Airport & 1 & 0.22 \\
\hline & Bus station & 2 & 0.44 \\
\hline \multirow{8}{*}{ Utility (U) } & Public square & 5 & 1.10 \\
\hline & Refuse processing plant & 2 & 0.44 \\
\hline & Sports center & 11 & 2.43 \\
\hline & Sewage treatment plant & 2 & 0.44 \\
\hline & Entertainment plaza & 4 & 0.88 \\
\hline & Hospital & 9 & 1.99 \\
\hline & Government organ & 6 & 1.32 \\
\hline & Government office & 4 & 0.88 \\
\hline Vacant (V) & Waste land & 1 & 0.22 \\
\hline \multirow{2}{*}{ Water/wetland (W) } & River or canal & 13 & 2.87 \\
\hline & Lake & 1 & 0.22 \\
\hline Total & & 453 & 100 \\
\hline
\end{tabular}

overpasses, bridges, roads, expressways, bus stops, train stations, airports, and bus stations; $T$ also includes limited access roadways (usually fenced), train tracks, airports, shipyards, etc. 'Utility' (U) includes public squares, refuse processing plants, sports centers sewage treatment plants, entertainment plazas, hospitals, government organs and government offices. 'Vacant land' (V) has no apparent use; boarded up buildings have been classified by the original designated use of the structure. Finally, 'water/wetland' (W) includes rivers, canal, and lakes.

In accordance with the descriptions above, a total of $38 \mathrm{sec}-$ ondary USUs were defined as specific land cover classes within each primary USUs types (see Table 1), and have been augmented by our ground-level knowledge of Beijing.

\section{Delineation of the boundaries for different structural units}

We initially used a stratified sampling protocol to select USUs. Thus, we used grids to sample evenly, and then chose one to four USUs randomly to act as representatives. First, two scenes of cloud-free SPOT 5 (Satellite Pour l'Observation de la Terre) images with spatial resolution of $10 \mathrm{~m}$ and acquisition dates of 30 August and 25 October 2002 were obtained. Both images were geometrically rectified by ground control points from already orthorectified images and then mosaiced using ERDAS Imagine ${ }^{\mathrm{TM}}$ software. We extracted images within the fifth ring road of Beijing and tilted into $1602 \mathrm{~km} \times 2 \mathrm{~km}$ grids. Second, the tiles were printed into $50 \mathrm{~cm} \times 40 \mathrm{~cm}$ size photos. Following our initial selection protocol, we realized that some sampling sites fell into lakes or large squares, whose socioeconomic factors could not really be assessed. Moreover, we found that there were thousands of USUs in this area, but limited USU map or data for sampling. To account for this lack of data, we selected the USUs based on the grids and chose one to four representatives in each USU type by the importance of the USUs, and then created the USUs boundaries for them. We acknowledge that compared to a true stratified random approach, our method may potentially introduce some sampling bias, but we tried to reduce the bias as much as possible by increasing the sampling size for the same USU type.

The boundary of each USU was determined on the printed photo by referring to Google Earth (accessed from June to July in 2010), Beijing City Atlas (BISM, 2005, scale 1:50,000), and on-the-spot surveys (including asking local people for a given USU's boundaries) Finally, referring to the SPOT 5 images, the boundaries were drawn on the images using ArcGIS 10 (Fig. 1). 
Imagery classification

An appropriate land cover classification system developed by Cadenasso et al. (2007) was adapted to identify land cover classes from the SPOT 5 image. All surfaces were classified into six categories: built-up land, woodland, grassland, mixed woodland and grassland, agricultural land, and water. With regard to the high spatial heterogeneity of urban environment lands, the object-oriented image analysis approach (OOIA) supported by Definiens Developer 7.0 was used to perform the land cover classification. This approach has the advantage of incorporating both spectral and spatial context information into imagery classification (Walker and Blaschke, 2008). The whole classification process comprises two main steps. First, the multi-resolution segmentation was used to derive image objects that satisfactorily allow for incorporation of shape, spatial relations and reflectance statistics into classification. This step is also used for "training" sample selection and subsequent classification. Second, a combination of standard nearest neighbor and fuzzy rule set, on the basis of spectral bands 1 through coupled with spatial relationships, was utilized to classify each image object to the most appropriate and precise categories. For this step, training samples for each class were derived from ancillary data, including aerial photographs, field surveys, and land use maps. Accuracy assessment was carried out using the error matrix with a stratified random sampling method. A total of 300 random points were sampled and compared with referenced field surveys and land use maps The overall accuracy and Kappa coefficient were 95.46 and 0.94 respectively. The final derived land cover map is shown in Fig. 1.

\section{Socioeconomic indicators obtained}

The year in which each secondary USU had been constructed or built was obtained by referring to its website portal or by visiting the actual site from June to September in 2010. We determined the "construction period" (the length of time a USU was under construction or being developed) by using 2010 minus the year when a given USU was established.

The housing prices of different residences were accessed from the website http://beijing.aifang.com/, with query time from May to July in 2010. The housing information (i.e., construction period, the specific storey of the house) of the link is accurate and up-todate. Only a few plots had no house price information, and for those rare cases, we referred to the local housing value evaluation center (i.e., http://www.zplh.net/) and interviewed more than 30 local people to calculate the average and avoid bias as much as possible. One plot represents single ownership in most parcels, although sometimes one plot has multiple owners, who are either located in different stories of a tall building and/or have been artificially grouped together because the boundaries changed rapidly due to the extremely fast pace of urbanization in Beijing. To account for this, the price of the actual property or real estate value in each plot for residential areas (R) were used for this study. In addition, the housing price was only limited to the houses located within each plot and represented an average for whole neighborhood in residential areas (R). Housing values for multifamily residences (M) were averaged.

We chose construction period and housing price as socioeconomic variables because: (1) the construction period and housing price are comprehensive for all USUs, and we readily obtained the data for these two variables for all USU, (2) the reliability of the data for these two variables is high, based on our investigation and website referencing, and (3) the data for the two variables are easier to obtain compared to data for the level of education, income, etc.
Green space percentage and socio-economic statistical analysis

There were 453 USUs sampled in total, but only the data for 264 USUs were used for analyses, due to the unavailability of satellite imagery for some areas. The land cover data (forest area, grassland, mixed forest and grass land and imperious land, etc.) within each USU and the 189 USUs are not interpreted into forest area, grassland, etc. within each USU. The work took place as follows: first, we selected 264 USUs and drew their boundaries, then, we interpreted the land cover and calculated the percentage for all 264 USUs. We chose one or two USU in each grid for 264 USUs. However, after this, we thought the number of USUs was not large enough to represent the entire urbanized area of Beijing, and thus we increased the number of USUs to three in each grid, bringing the total to 453. But in the last step, the land cover for the added 189 USUs was not calculated because the student who interpreted the remote sensing graduated. So we did not have the land cover data of the rest 189 USUs. But for heuristic purposes, we kept 453 USUs in the first part of the analysis to explore all USU categories in Beijing.

Therefore, while our USU classification system includes 12 primary USU types and 38 secondary USU types (Table 1 ), only 8 primary USU types and 21 secondary USU land cover patterns were used for subsequent analysis. The percentage green space cover was calculated by taking the area for woodland, grassland, mixed woodland and grassland, and agricultural land as a percentage of the whole area of each secondary USUs. We averaged the percentage of each land cover based on USU types, and aggregated woodland, grassland, and mixed woodland-grassland as urban green space.

Linear regressions were performed to analyze the correlation between the construction period (2002 minus the start of construction) and green space percentage in colleges/universities universities and parks, as the sample sizes were more than 30 all of these areas, which was sufficient to carry out statistical analysis.

\section{Results}

\section{The primary urban structural units in Beijing}

In total, 453 urban structural units were analyzed (Fig. 1), and these could be categorized within the 12 primary types (Fig. 2 ). The most common primary USUs were utility $(\mathrm{U})(n=8,21.05 \%$ of all primary types), followed by transportation (T) $(n=6,15.79 \%)$ and institutional (I) $(n=6,15.79 \%)$. The common USUs are only common to the sample; any given sample is not necessarily representative of the composition of all USUs. The least frequent primary types included cemeteries $(C)(n=1,2.63 \%)$, golf courses $(G)(n=1,2.63 \%)$, multi-family residential $(\mathrm{M})(n=1,2.63 \%), \operatorname{park}(\mathrm{P})(n=1,2.63 \%)$ and vacant land $(\mathrm{V})(n=1,2.63 \%)$.

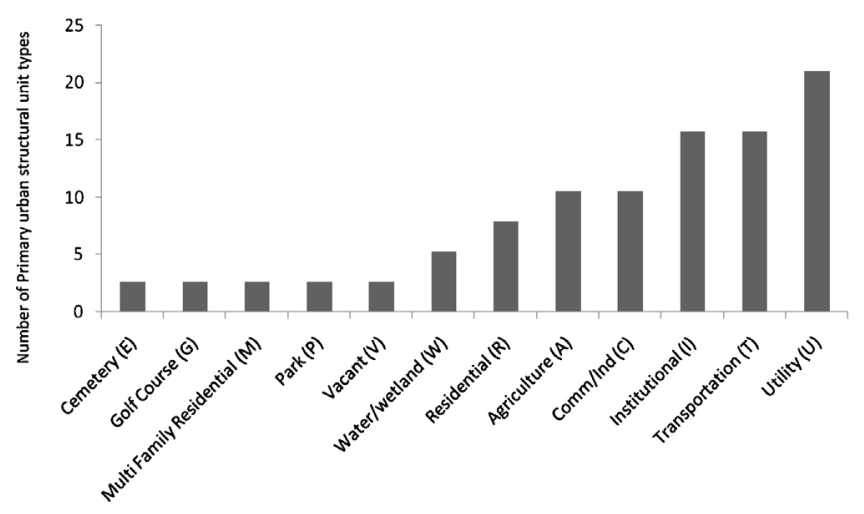

Fig. 2. The number of primary urban structural units in Beijing, China. 
Table 2

Land cover area $\left(\mathrm{km}^{2}\right)$ in the 21 secondary urban structural units.

\begin{tabular}{|c|c|c|c|c|c|c|c|}
\hline & Built land & Woodland & Grassland & $\begin{array}{l}\text { Mixed woodland and } \\
\text { grassland }\end{array}$ & Water & Agricultural land & Total area \\
\hline Museum & 0.047 & 0.00465 & 0.003775 & 0.001425 & 0 & 0 & 0.057225 \\
\hline Attached green space & 0.048 & 0.05159 & 0.03613 & 0.02632 & 0.00053 & 0.00519 & 0.16737 \\
\hline Cemetery & 0.053 & 0.186133333 & 0.027166667 & 0.033666667 & 0 & 0.0051 & 0.305433333 \\
\hline Primary and middle schools & 0.067 & 0.2815 & 0.022366667 & 0.031766667 & 0.00312667 & 0 & 0.140726667 \\
\hline Hospital & 0.077 & 0.01934 & 0.00358 & 0.00156 & 0 & 0 & 0.10152 \\
\hline Park & 0.085 & 0.160615094 & 0.054058491 & 0.044981132 & 0.02947547 & 0.004809434 & 0.379281132 \\
\hline General institution & 0.092 & 0.018644444 & 0.005555556 & 0.001377778 & 0 & 0 & 0.117933333 \\
\hline Government organs & 0.093 & 0.03842 & 0.00386 & 0.00042 & 0.0408 & 0 & 0.17656 \\
\hline Enterprise & 0.111 & 0.053192857 & 0.026121429 & 0.0084 & 0.00014286 & 0.012807143 & 0.21125 \\
\hline Farmland or orchard & 0.115 & 0.11562 & 0.08668 & 0.04146 & 0.00098 & 0.02134 & 0.38104 \\
\hline Road and express & 0.116 & 0.047077778 & 0.009988889 & 0.005533333 & $7.7778 \mathrm{E}-05$ & 0 & 0.178611111 \\
\hline Hotel & 0.12 & 0.0198 & 0.000833333 & 0.000633333 & 0 & 0 & 0.141 \\
\hline Logistics center & 0.126 & 0.0216 & 0.03088 & 0.0046 & 0 & 0 & 0.18278 \\
\hline Low density & 0.132 & 0.023269767 & 0.033930233 & 0.016811628 & 0.00249302 & 0.006830233 & 0.215425581 \\
\hline Siheyuan (courtyard) & 0.134 & 0.062 & 0.000966667 & 0.000133333 & 0.05463333 & 0 & 0.251733333 \\
\hline High density residential area & 0.137 & 0.062245946 & 0.024494595 & 0.01322973 & 0.00988649 & 0 & 0.24732973 \\
\hline Entertainment plaza & 0.154 & 0.01515 & 0.024775 & 0.016225 & 0 & 0 & 0.210275 \\
\hline Public square & 0.155 & 0.17266 & 0.098 & 0.08258 & 0.00346 & 0 & 0.51178 \\
\hline Research institution & 0.21 & 0.0605875 & 0.0212875 & 0.0075125 & 0.0000375 & 0.0025625 & 0.3019 \\
\hline Train station & 0.216 & 0.04755 & 0.0291 & 0.02855 & 0.00275 & 0 & 0.323925 \\
\hline Sports center & 0.22 & 0.08075 & 0.081116667 & 0.024533333 & 0.00673333 & 0 & 0.413133333 \\
\hline College/university & 0.224 & 0.107245714 & 0.055017143 & 0.024065714 & 0.00274 & 0 & 0.41286 \\
\hline
\end{tabular}

Secondary urban structural units and their cover in Beijing

The 453 urban structural units were divided into 38 different secondary urban structural units (Table 1 ). High-density residential areas ( $n=94,20.75 \%$ of all secondary types) were the most common secondary urban structural units, followed by low-density residential areas and parks, which account for $14.57 \%(n=66)$ and $10.38 \%$ $(n=47)$ respectively. The least common secondary urban structural units included woodland, nurseries, bus stops, airports, waste lands, and wetlands; there was only one representative of each of these, each accounting for $0.22 \%$ of all secondary USUs, respectively (Table 1).

The land cover percentage differed among the 21 secondary urban structural units (Table 2). The percentage of built-up area is the highest for the areas designated "hotel" $(84.92 \% \pm 9.86 \%, n=3)$, and the lowest in cemeteries $(16.44 \% \pm 6.03 \%, n=3)$. The percentage of woodland area is the highest in primary and middle schools $(69.43 \% \pm 9.86 \%, n=34)$, and the lowest in entertainment plazas $(7.20 \% \pm 2.03 \%, n=4)$. The percentage of grassland area is the highest in farmland or orchards $(22.75 \% \pm 2.36 \%, n=7)$, and the lowest in Siheyuan or Courtyard $(0.38 \% \pm 0.03 \%, n=2)$. The percentage of woodland area is the highest in public squares $(16.14 \% \pm 2.36 \%$, $n=5)$, and the lowest in entertainment plazas $(0.05 \% \pm 0.01 \%, n=2)$ (Table 2).

\section{Green space percentage in secondary urban structural units}

The green space percentage within the different secondary urban structural units also varied (Fig. 3). The percentage of green space is the highest in middle and primary school units $(82.90 \% \pm 5.69 \%, n=34)$, and the lowest in museum areas $(12.71 \% \pm 6.58 \%, n=6)$.

\section{Relationship between green space cover and construction period}

There is no significant linear relationship (Fig. 4) between the construction period and green space percentage in colleges/universities $(R=0.045, p=0.806>0.05)$, nor is there a significant linear relationship (Fig. 4) between construction period and green space percentage in parks $(R=0.13, p=0.43>0.05)$.
Relationship between the house price and green space percentage in residential areas

The relationship between the house price and green space percentage in residential areas shows an inverted "U"-shaped curve: that is, residential house prices gradually increased with increasing green space, reaching a peak, after which the price began to fall with the continued increase in green space percentage (Fig. 5). The specific equation is: $f=17736.45+348.21 x-4.15 x^{2} \quad(p=0.0022)$, indicating significant relationship between house price and the greening percentage.

\section{Discussion}

\section{Land use in different urban structural units}

We developed a detailed two-level urban structural unit (USU) categorization system that can be very useful in urban planning. USUs are the functional units in cities that are under the control of various entities, and play a specialized role in supporting our lives. For example, research institutes and universities are the main government-owned educational facilities that provide research and educational opportunities; residential areas are

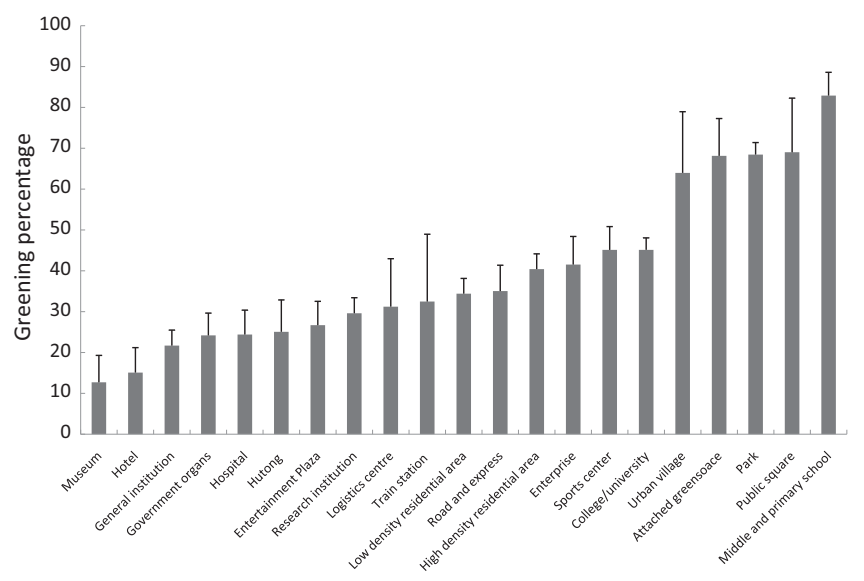

Fig. 3. Green space percentages in secondary urban structural units. 


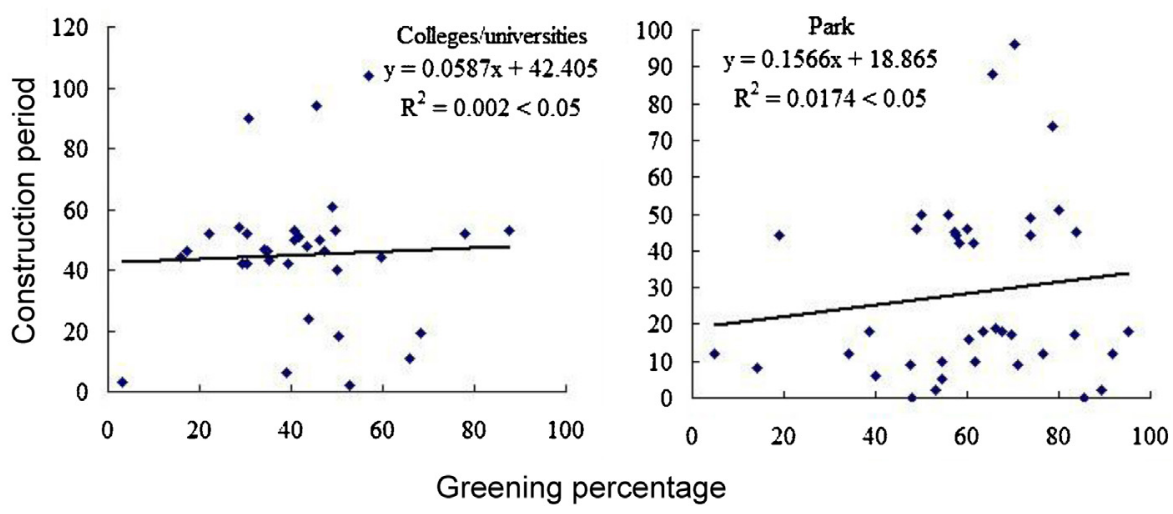

Fig. 4. The relationship between greening percentage and construction period in colleges, and parks.

mostly privately owned regions where people live. Previous urban land use/cover studies either focused on how human are using land (land use) or what ecological functions can generate from land (land cover), and little emphasis have been placed on the human-oriented functions of urban land parcels. In our study, we applied a combination of remote sensing technique and spatial analysis to quantify to land cover composition, in particular urban greenness, among different USUs in the central urban regions of Beijing. Our system provided a sound basis to incorporate economic and social preference into urban land studies.

The USUs we described here share many similarities with the Urban Forest Effects (UFORE) Model: Field Data Collection Manual (UFORE, 2012), which included 12 primary types of land uses. However, based on the primary types, we further classified the land use into secondary USU types; e.g., the secondary types of residential area included urban villages, low-density residential area, and Siheyuan (Courtyard). An "urban village" is a special land cover type characteristic of rapid urbanization in China: with accelerated urbanization, some villages that were initially rural become embedded into the expanding Beijing (Jia, 2010). "Siheyuan" is a kind of square or rectangular enclosed courtyard, mainly distributed in the second ring of Beijing (Siheyuan, 2012). Such courtyards are over 2000 years old. This detailed USU classification system also provided a basis to link land use with land cover. The sampling sites in each plot were chosen mainly based on our own knowledge of them, even though Beijing has thousands of USUs. This nonrandom sampling method might result in some statistical errors regarding across the entire city, although we did have a large knowledge base

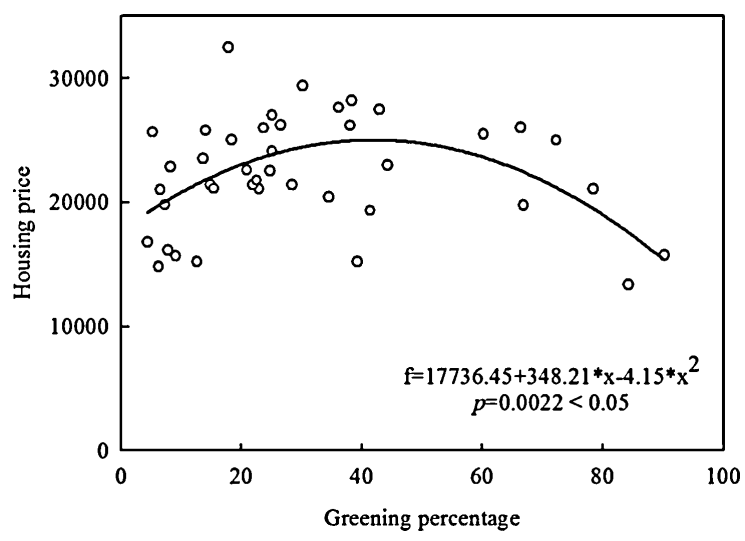

Fig. 5. The relationship between housing price and its green space percentages in residential areas. and expertise regarding this work, and believe that our findings are robust and representative.

Our results showed that there was a considerable variation in urban greenness among different USUs (ranging from $10 \%$ to $80 \%$ ), suggesting that the utility and function of USUs might be important co-occurring economic and social preference factors that determine the variations of urban greenness. For example, there was less greening in entertainment plaza and hotels, which are commonly located in city center or commercial regions, whereas a higher percentage of green space was found in parks, urban villages and public squares. We also found that middle school and primary school areas had the most green space, reflecting that youth education is a major concern in terms of urban greenness, so much so that some of the green spaces had been artificially increased. Other educationrelated units, such as colleges and universities, also had an overall higher percentage of green space. On the contrary, we found that USUs like hospitals, museums, and governmental organizations all of which could benefit their residents from a health perspective by being more green - had a much lower level of greenness (less than 20\%). Different USUs thus adopt different greening policies for their different functions.

Our study revealed that the impervious surface percentage and the average surface area of residential areas (R) and multifamily residences $(\mathrm{M})$ are higher in Beijing than those in western cities. The maximum impervious surface per parcel in residential high density multifamily was 50\% in Bloomington, USA (Mincey et al., 2013). However, in our study, the percent impervious cover in residential areas in Beijing is up to $65.6 \%(\mathrm{SE}=2.1 \%)$ in residential areas $(\mathrm{R})$ and $59.6 \%(\mathrm{SE}=1.4 \%)$ in multifamily residences $(\mathrm{M})$. Within urban/community areas in Connecticut, USA, Nowak and Greenfield (2012) found that the value for percent tree cover $(35.1 \%$, $\mathrm{SE}=0.4 \%$ ) is similar to the national value, but that percent impervious cover is significantly higher $(17.5 \%, \mathrm{SE}=0.3 \%)$ than the national value. The average zone size is $0.191 \mathrm{~km}^{2}(n=36)$ in Bloomington, USA (Mincey et al., 2013), however, in Beijing, the average area of high density multifamily is $0.247 \mathrm{~km}^{2}(n=37)$. Therefore, compared with urban greening space percentage in cities of developed countries, Beijing has a lower green space percentage.

However, the green space increasing rate was faster in Beijing than some western cities. The urban tree and palm cover was $12.4 \%$ in 2004, but tree and palm cover was $14 \%$ in 2008 in Miami, USA (Zhao et al., 2010b; Szantoi et al., 2012), it was only changed $1.6 \%$ in 4 years. At the same time, the percentage of greening land area in 2004 was $63.7 \%$, but the percentage of greening land area in 2008 was $75 \%$ (BMBS, 2009) in Beijing, it increased by $11.4 \%$ in the past 4 years. Therefore, although Beijing has much more impervious surface percentage, it has much increasing potential and rate than western cities. 
Factors affecting the green spaces pattern changes in Beijing

Studies have shown that socio-economic factors are the most important factors driving changes in the China urban forest, accounting for $54 \%$ of the variation, followed by natural factors, which explain $28 \%$ of the variation, and finally by human disturbance stress factors, which account for $18 \%$ of the variation (Zhang, 2010). Many other studies cite socio-economic factors as a dominant force driving urban green space changes (e.g., Iverson and Cook, 2000; Hope et al., 2003; Grove et al., 2006; Troy et al., 2007; Escobedo et al., 2006; Kirkpatrick et al., 2007; Conway and Hackworth, 2007; Zhang, 2010; Boone et al., 2010; Szantoi et al., 2012). More affluent places have a greater percentage of green space simply because more money can be invested in greening initiatives as opposed to basic needs, a phenomenon described as the "Luxury Effect" (Hope et al., 2003); this phenomenon, while not necessarily given this specific name, was also reported in other cases (Iverson and Cook, 2000; Escobedo et al., 2006; Luck et al., 2009; Troy et al., 2012; Cohen et al., 2012). Our study supplemented more evidence demonstrating how various social and economic factors influence urban green space in a rapidly expanding city. Our results showed that there was no significant relationship between construction period and green space percentage in USUs such as colleges and universities and parks (Fig. 5), indicating that for these USUs, construction time is not an important factor determining urban green space. Once established, green space (greening) construction in each USU is considered complete, and will only fluctuate slightly following establishment.

The housing price reflects the income level of its residents (Guo et al., 2007). The more affluent residents might be able to provide more resources for their residential green space, and in turn, residential places with higher greening cover and plant diversity will attract more affluent buyers (Hope et al., 2003; Grove et al., 2006; Luck et al., 2009; Boone et al., 2010). House price varies by landscape type: attractive landscape types were shown to attract a premium of $5 \pm 12 \%$ over less attractive environmental settings; a large tree in the front yard of the residence could increase the housing sales price by $0.88 \%$ (Anderson and Cordell, 1988). Similarly, the configuration of courtyard trees made the house prices in Athens, Georgia, US increase by $15-25 \%$ (Anderson and Cordell, 1988). In fact, Luttik (2000) found that the largest increases in house prices (up to 28\%) could be attributed to environmental factors. In our study, we found an inverted relationship between housing costs and urban greenness percentage. Housing prices initially increase with greening percentages for new houses in real estate openings: the area available for residential construction is fixed, and so the area for green space rises as the area for new buildings is concurrently reduced. In order to maintain high profits, the housing prices would thus rise. In many older residences, however, the green space percentage can be quite high, especially if the land is augmented by new young trees or grasses over the years: these older dwellings would not be as expensive as newer residences.

Any time lag between neighborhood socioeconomic characteristics and vegetation in urban ecosystem needs to be considered when we explore the relationships between them (Pickett and Cadenasso, 2006; Luck et al., 2009). In our study, the SPOT 5 image was acquired in 2002, the USUs were chosen in 2010, and the socioeconomic variables (housing prices and construction period) were accessed in 2010. In a rapidly changing environment like Beijing, 8 years represents a significant period of time. We noted that the USUs and their corresponding socio-economic factors had changed after 8 years of rapid urban development. Ideally, we would determine the relationship between land cover and its social-economic factors in both 2002 and 2010 respectively, and test whether a time delay also exists in Beijing as reported by Pickett and Cadenasso (2006) and Luck et al. (2009). There was no significant linear correlation between the greening percentage and the construction year in colleges and parks in 2002, and there was no significant non-linear correlation between the greening percentage and the construction year when using the time of 2010. The sample number of high-density residential areas is less than 30 when using the time 2002, because most highly-density residential areas were built after 2002, so we did not count high-density residential areas in Fig. 4.

However, we had irreparable gaps in our data (e.g., we could no longer obtain the housing price of each USU in 2002), and thus the analysis only explains the correlation of the land cover in 2002 to the social economic factors in 2010 in each USUs in Beijing. This unfortunate time lag in our data does, though, reflect the importance of the overall data collection year by year in long-term ecological studies. Therefore, as one of the long-term monitoring stations nested in CERN (Chinese Ecological Research Network), the Beijing Urban Ecosystem Research Station will now monitor the socioeconomic variables on a continuing basis in order to generate long-term data.

\section{Conclusion}

As a city in a developing country, Beijing is undergoing rapid urbanization. Urban green spaces benefit the urban environment (e.g., dust removal, a reduced "heat island" effect, etc.). For this reason, and because impervious land cover threatens to dominate the city, every effort should be made to increase green spaces in Beijing. Socioeconomic factors are the main factors affecting urban greening (up to 54\%, Zhang, 2010), therefore, sorting out the key socioeconomic variables and explore their function will be a priority when considering urban greening planning or future development. Analyzing the LULC patterns across different USUs will help to quantitatively analyze the heterogeneity of different USUs (Buyantuyev, 2008). Furthermore, this type of analysis provides some basic data for future long-term urban planning and development. Therefore, for a rapidly urbanized city, it is important that fixed plots are selected and that LULC changes over the long term are monitored.

\section{Acknowledgements}

We are grateful to Ran-Hao Sun and Hua Wang for their help with Figs. 1 and 5. The authors thank the two anonymous reviewers for their constructive suggestions on the first version of this manuscript. This study was funded by the National Natural Science Foundation of China (41201049 and 41030744) and was also supported by funding from the State Key Laboratory of Urban and Regional Ecology, and special funds for forestry research and public service industry (201304301).

\section{References}

Alberti, M., 2005. The effects of urban patterns of ecosystem function. International Regional Science Review 28, 168-192.

Alberti, M., Marzluff, J.M., 2004. Ecological resilience in urban ecosystems: linking urban patterns to human and ecological functions. Urban Ecosystems 7, 241-265.

Anderson, L.M., Cordell, H.K., 1988. Influence of trees on residential property values in Athensm, Georgia (U.S.A.): a survey of actual sales prices. Landscape and Urban Planning 15, 153-164.

BISM (Beijing Institute of Surveying and Mapping), 2005. Atlas of Beijing Urban. Hunan Cartographic Publishing House, Changsha (in Chinese).

BMBS (Beijing Municipal Bureau of Statistics, NBS Survey Office in Beijing), 2009 Beijing Statistical Yearbook 2009. China Statistics Press, Beijing (in Chinese).

Boone, G.C., Cadenasso, L.M., Grove, M.J., Schwarz, K., Buckley, G.L., 2010. Landscape, vegetation characteristics, and group identity in an urban and suburban watershed: why the 60s matter. Urban Ecosystems 13, 255-271.

Breuste, J., Qureshi, S., 2011. Urban sustainability, urban ecology and the Society for Urban Ecology (SURE). Urban Ecosystems 14, 313-317. 
Breuste, J., Wohlleber, S., 1998. Goals and measures of nature conservation and landscape protection in urban cultural landscapes of Central Europe - examples from Leipzig. In: Breuste, J., Feldmann, H., Uhlmann, O. (Eds.), Urban Ecology. Springer-Verlag, Berlin/Heidelberg, pp. 676-682.

BSRC (Beijing Science Research Center), 2009. Evaluation Research of the Urbanization Process in Beijing, Retrieved from: http://www.bjkw.gov.cn/ n1143/n1240/n1465/n2216/n3710709/3711264.html (09.03.10).

Buyantuyev, A., 2008. Effect of urbanization on landscape pattern and ecosystem function in Phoenix: a multiscale study. Arizona State University, Phoenix, AZ (PhD Thesis).

Cadenasso, M.L., Pickett, S.T.A., Schwarz, K., 2007. Spatial heterogeneity in urban ecosystems: reconceptualizing land cover and a framework for classification. Frontiers in Ecology and Environment 5, 80-88.

Chen, W.Y., Jim, C.Y., 2008. Assess and valuation of the ecosystem services provided by urban forests. In: Carreiro, M.M., Song, Y.C., Wu, J. (Eds.), Ecology, Planning, and Management of Urban Forests International Perspectives. New York, Springer, pp. 53-83.

Cohen, M., Baudoin, R., Palibrk, M., Persyn, N., Rhein, C., 2012. Urban biodiversity and social inequalities in built-up cities: new evidences, next questions. The example of Paris, France. Landscape and Urban Planning 106, 277-287.

Conway, T.M., Hackworth, J., 2007. Urban pattern and land cover variation in the greater Toronto area. Canadian Geographer 51, 43-57.

Davies, R.G., Barbosa, O., Fuller, R.A., Tratalos, J., Burke, N., Lewis, D., Warren, P.H., Gaston, K.J., 2008. City-wide relationships between green spaces, urban land use and topography. Urban Ecosystems 11, 269-287.

Dunn, C.P., Sharpe, D.M., Guntenspergen, G.R., et al., 1991. Methods for analyzing temporal changes in landscape pattern. In: Turner, M.G., Gardener, R.H. (Eds.), Quantitative methods in Landscape Ecology. Springer-Verlag, New York, pp. 173-198.

Escobedo, F.J., Nowak, D.J., Wagner, J.E., et al., 2006. The socioeconomics and management of Santiago de Chile's public urban forests. Urban Forestry and Urban Greening 4, 105-114.

Grimm, N.B., Grove, J.M., Pickett, S.T.A., Redman, C.L., 2000. Integrated approaches to long-term studies of urban ecological systems. BioScience 50 571-584.

Grimm, N.B., Faeth, S., Golubiewski, N.E., et al., 2008. Global change and the ecology of cities. Science 319, 756-760.

Grove, J.M., Troy, A., O'Neil-Dunne, R.J.P.M., et al., 2006. Characterization of households and its implications for the vegetation of urban ecosystems. Ecosystems 9, 578-597.

Guo, J., Fang, Y., Zhu, B., 2007. Study of selection in price-earnings ratio indication factors. Journal of Anhui Agricultural Sciences 35, 5967-5968 (in Chinese, with English abstract).

Gustafson, E.J., 1998. Quantifying landscape spatial pattern: what is the state of the art? Ecosystems 1, 143-156.

Hope, D., Gries, C., Zhu, W., et al., 2003. Socioeconomics drives urban plant diversity. Proceedings of the National Academy of Sciences, USA 100, 8788-8879.

Iverson, L.R., Cook, E.A., 2000. Urban forest cover of the Chicago region and its relation to household density and income. Urban Ecosystems 4, 105-124.

Jia, Y., 2010. Reform and development of urban village in China. Shaanxi Building 179, 13-15 (in Chinese).

Kim, K.H., Pauleit, S., 2007. Landscape character, biodiversity and land use planning: the case of Kwangju City Region, South Korea. Land Use Policy 24 264-274

Kirkpatrick, J.B., Daniels, G.D., Zagorski, T., 2007. Explaining variation in front gardens between suburbs of Hobart, Tasmania, Australia. Landscape and Urban Planning 79, 314-322.

Li, H., Wu, J., 2007. Landscape pattern analysis: key issues and challenges. In: Wu, J. Hobbs, R. (Eds.), Key Topics in Landscape Ecology. Cambridge University Press, Cambridge, pp. 39-61.

Luck, W.G., Smallbone, L.T., O'Brien, R., 2009. Socio-economics and vegetation change in urban ecosystems: patterns in space and time. Ecosystems 12 604-620.

Luttik, J., 2000. The value of trees, water and open space as reflected by house prices in the Netherlands. Landscape and Urban Planning 48, 161-167.
Ma, S.J., Wang, R.S., 1984. The social-economic-natural complex ecosystem. Acta Ecologica Sinica 4, 1-9 (in Chinese with English abstract)

Markus, K., Jürgen, G., Christoph, B., Bruno, R., Franz, R., 2006. World map of the Köppen-Geiger climate classification updated. Meteorologische Zeitschrift 15 259-263.

Mincey, S.K., et al., 2013. Zoning, land use, and urban tree canopy cover: the importance of scale. Urban Forestry \& Urban Greening, http://dx.doi.org/10.1016/j.ufug.2012.12.005.

Nowak, D.J., Greenfield, E.J., 2012. Tree and impervious cover in the United States Landscape and Urban Planning 107 (1), 21-30.

Pickett, S.T.A., Cadenasso, M.L., 2006. Advancing urban ecological studies: frameworks, concepts, and results from the Baltimore Ecosystem Study. Australian Ecology 31, 114-125.

Pickett, S.T.A., Cadenasso, M.L., Grove, J.M., et al., 2001. Urban ecological systems: linking terrestrial ecological, physical, and socioeconomic components of metropolitan areas. Ecology, Evolution, and Systematics 32, 127-157.

SBBC (Statistical Bureau of Beijing City), 2008. Beijing Statistical Yearbook. China Statistics Press, Beijing (in Chinese).

Siheyuan, 2012. Retrieved from: http://baike.baidu.com/view/13973.htm (04.12.12).

Szantoi, Z., Escobedo, F., Wagner, J., Rodriguez, J.M., Smith, S., 2012. Socioeconomic factors and urban tree cover policies in a subtropical urban forest. GIScience \& Remote Sensing 49, 428-449.

Troy, R.A., Grove, J.M., Jarlath, P.M., et al., 2007. Predicting opportunities for greening and patterns of vegetation on private urban lands. Environmental Management 40, 394-412.

Troy, R.A., Groveb, J.M., O’Neil-Dunnea, J., 2012. The relationship between tree canopy and crime rates across an urban-rural gradient in the greater Baltimore region. Landscape and Urban Planning 106, 262-270.

2011. Urban Forest Effects (UFORE) Model: Field Data Collection Manual, Retrieved from: http://www.ufore.org/using/03-00.html (10.10.11).

Walker, J.S., Blaschke, T., 2008. Object-based land-cover classification for the Phoenix metropolitan area: optimization vs. transportability. International Journal of Remote Sensing 29 (7), 2021-2040.

Wang, R., Liu, J., 2010. Urban ecology and ecological human settlements construction. Modern Urban Study 3, 28-31 (in Chinese with English abstract).

Wang, R.S., Ouyang, Z.Y., 2012. Social-economic-natural complex ecosystem and sustainability. Bulletin of Chinese Academy of Sciences 27, 337-345 (in Chinese with English abstract)

Wang, Y., Li, J., Li, S., et al., 2004. Impact of human disturbances on urban plant diversity. Chinese Journal of Ecology 23, 102-104 (in Chinese with English abstract)

Wang . H. Lopez-Pujol, J., Meyerson, A.L., Qiu, J., Wang X., Ouyang Z, 2011. Biological invasions in rapidly urbanizing areas: a case study of Beijing, China. Biodiversity Conservation 20, 2483-2509.

Wang, H., MacGregor-Fors, I., Lopez-Pujol, J., 2012. Warm-temperate, immense, and sprawling: plant diversity drivers in urban Beijing, China. Plant Ecology 213 (6), 967-992.

$\mathrm{Wu}, \mathrm{J} ., 2008$. Making the case for landscape ecology: an effective approach to urban sustainability. Landscape Journal 27, 41-50.

Xiao, R., 2006. Landscape pattern change and urban heat island effect in Beijing Graduate University of Chinese Academy of Sciences, Beijing, pp. 26-42 (Doctoral dissertation)

Yeh, C.-T., Huang, S.-L., 2009. Investigating spatiotemporal patterns of landscape diversity in response to urbanization. Landscape and Urban Planning 93 (2009), 151-162.

Yuan, F., Bauer, M.E., 2007. Comparison of impervious surface area and normalized difference vegetation index as indicators of surface urban heat island effects in Landsat imagery. Remote Sensing of Environment 106, 375-386.

Zhang, Y., 2010. Evaluation of Environmental Benefits of Urban Forest in China, Beijing. China Forestry Publishing House, Beijing.

Zhao, J., Ouyang, Z., Zheng, H., et al., 2010a. Plant species composition in green spaces within the built-up areas of Beijing, China. Plant Ecology 209, 189-204.

Zhao, M., Escobedo, F., Staudhammer, C., 2010b. Spatial patterns of a subtropical, coastal urban forest: implications for land tenure, hurricanes, and invasives. Urban Forestry \& Urban Greening 9 (3), 205-214. 